\title{
A INTEGRAÇÃO DE TECNOLOGIAS DIGITAIS NO ENSINO DA MATEMÁTICA: UMA ABORDAGEM SOBRE O USO DO SOFTWARE GEOGEBRA NO ENSINO DE ÁLGEBRA
}

Marcilene Zerbone Zucolotto*

\section{RESUMO}

Este presente artigo científico tem por objetivo apresentar os resultados de uma pesquisa sobre o uso do software GeoGebra como uma ferramenta digital que favorece a aprendizagem matemática de ensino de álgebra. A metodologia se apoia na aplicação de um questionário com 3 (três) perguntas para os discentes das duas primeiras séries do ensino médio do turno matutino da EEEFM "Padre Antônio Volkers" em Marilândia, que objetiva investigar como o uso do software contribui para melhorar a aprendizagem de matemática para eles. Essa investigação resultou em apresentação de resultados satisfatórios, cujos esforços permitiram realizar uma mini-oficina de GeoGebra na instituição, que permitiu dinamizar o ensino de matemática, se tornando também, junto com o software, um elemento condicionante para a melhoria da aprendizagem. As recentes gerações dos discentes sentem-se mais propensas a utilizar todo tipo de tecnologias móveis, telecomunicativas e interativas como os smartphones conectados à internet, o que explica que elas aprendem melhor com esses recursos. $O$ docente precisa também acompanhar a evolução no ensino de matemática para ser cada vez mais inovador e estimulador da educação.

Palavras-chave: Software GeoGebra. Mini-oficina. Aprendizagem matemática. Álgebra.

\footnotetext{
* Mestre em Ciências da Educação pela Facultad Interamericana de Ciencias Sociales. Asunción-PY. Contatos: E-mail: marcilenez@hotmail.com Tel: (27) 99921-4357.
} 


\section{INTRODUÇÃO}

No mundo atual, marcado substancialmente pela presença sempre crescente e constante de tecnologias modernas em praticamente todos os ramos da sociedade humana, a utilização de um deles elementos, os chamados softwares, programas computacionais que realizam determinadas atividades ou todas elas em foco específico, possibilitam a dinamizar as atividades virtuais de forma mais abrangente e até de forma mais rápida e precisa, o que configura que o ser humano está vivendo em uma era de grandes conquistas no plano do conhecimento, que foram iniciadas séculos e até mesmo milênios atrás.

Os softwares possuem aplicabilidade em praticamente todas as áreas do conhecimento humano. Na educação, esses elementos possibilitaram uma rápida transformação e reformulação da arte de ensinar, que exige aqui nesta pesquisa uma abordagem especial, que ilustra como a utilização de elementos tecnológicos digitais e informacionais são imprescindíveis para a dinamização do ensino e sua constante evolução.

Nesse contexto, discentes precisam indagar, discutir e estabelecer relações por meio do uso das modernas tecnologias. Ao lidar com isso, os discentes se sentirão estimulados a querer buscar soluções para inúmeros problemas cotidianos de forma mais prazerosa e estimulante. O uso dos softwares, como o GeoGebra em sala de aula, vem a promover um encontro entre teoria e prática e revolucionar ainda mais o modus operandi de se dar aulas.

Fava (2014) informa que cada vez mais o mundo está substituindo as mídias tradicionais por aquelas que se caracterizam ou são participativas e interativas, pois estas últimas realizarão uma transformação cultural à medida que os discentes sejam incentivados a procurar novas informações e construções de conhecimento. É imperioso que também o docente acompanhe o ritmo das transformações para continuar promovendo educação de qualidade com domínio de habilidades e competências.

O objetivo geral deste artigo é apresentar um estudo sobre o uso do software geogebra no ensino de álgebra em uma instituição escolar no município de Marilândia, Espírito Santo, mediante utilização de uma metodologia que permite realizar uma pesquisa de campo. 
Os objetivos específicos são: conhecer o software GeoGebra; aplicar um questionário para os discentes da instituição escolar pesquisada; apresentar os dados coletados; e discutir os dados sob a ótica do conhecimento matemático moderno.

A metodologia adotada foi de investigar o domínio dos discentes através de aplicação de um questionário com três perguntas sobre o GeoGebra no ensino de álgebra para duas turmas do ensino médio do turno matutino da escola estadual "Padre Antônio Volkers" em Marilândia. Destaca-se também a aplicação de uma mini-oficina de GeoGebra no laboratório da instituição escolar, para o aprimoramento do manuseio das álgebra do software. As análises metodológicas também se servem como instrumento precioso de avaliação dos discentes e apontar quais os pontos que necessitam ser melhorados para a aprendizagem.

\section{FUNDAMENTAÇÃO TEÓRICA}

\subsection{O GeoGebra}

O GeoGebra - terminologia que agrega as palavras geometria e álgebra - foi criado em 2001 pelo matemático austríaco Markus Hohenwarter. Ao longo dos anos, como mencionam Borba; Silva; Gadanidis (2016), esse produto foi se desenvolvendo agregando novos comandos e álgebra e se consolidando como uma das principais tecnologias que inovaram o ensino de matemática.

O GeoGebra constitui-se um software de matemática que realiza cálculos dinâmicos, reunindo recursos de geometria, álgebra, tabelas, gráficos, probabilidade, estatística e cálculos simbólicos em um único ambiente, com a vantagem didática de representar as características geométricas e algébricas de um mesmo objeto.

Araújo; Nóbriga (2010) destacam que esse software é de fácil aquisição - é distribuído gratuitamente em muitos websites - e manuseio quase acessível para os usuários de pequeno conhecimento de programação. Além disso, o GeoGebra compila as plataformas de geometria dinâmica e dos sistemas de computação algébrica, o que revisita perspectivas importantes da segunda fase como a 
experimentação com tecnologias e a visualização. A distribuição gratuita do software é regida pelos termos da General Public License para fins não comerciais.

Giraldo; Caetano; Mattos (2012) dizem que os softwares, como o GeoGebra, que operam cálculos matemáticos, têm que apresentar, em primeiro lugar, possibilidades de uso de ambientes de geometria dinâmica no ensino de matemática, pois isso permite uma aprendizagem que leva o indivíduo a desenvolver raciocínio matemático dedutivo.

A geometria, segundo Bernardes; Notare (2018) se contribui um elemento que contribui para o desenvolvimento de habilidades percepção espacial, muito importante para realização de contagem e de observação do espaço. Por meio de exploração das formas e cálculos geométricos, os discentes desenvolvem percepção do mundo em que está inserido e conseguirá descrevê-lo, representa-lo e localizar-se nele.

Esse software de matemática foi desenvolvido justamente para resolver problemas relacionados com a aplicabilidade geométrica no cotidiano, permitindo ao usuário estabelecer cálculos muito precisos entre as medidas e visualizar diversas figuras relacionadas com as álgebra matemáticas. Estudar geometria se constitui a base para estudos diversos, como a engenharia, o funcionamento de máquinas, o comportamento de vários organismos vivos, a estatística e até de localizações. Além disso, possibilita operar gráficos com a geometria, planilhas, probabilidades e diversas outras álgebra matemáticas, tanto básicas quanto avançadas, além de permitir download de outros aplicativos fornecidos pelo website desse software.

Há vários tipos de versões do software GeoGebra disponíveis atualmente na internet para download gratuito, que é fornecido pelo próprio website e por outros, como Softsonic e Olhar Digital, que contemplam desde o aplicativo clássico até o de 3D, sendo este recurso recomendado o uso do GeoGebra Classic 5 (ARAÚJO; NOBRIGA, 2010).

Segundo Sabino; Kon (2009), o software GeoGebra permite que o usuário tenha a liberdade de executar seus programas para quaisquer propósitos, de adaptá-los às outras necessidades de conhecimento matemático, além de ser gratuito e continuamente atualizado pela empresa que o desenvolveu através de seu próprio website. Funciona em linguagem de programação Java, que possibilita que esteja disponível em várias plataformas operacionais, como o Windows, Linux e 
Android, por exemplo, além de também ser manipulável através de outras mídias eletrônicas mais portáteis, como os tablets e os smartphones.

Hohenwarter (2018), que criou o software, informa que percebeu que a geometria possibilita uma gama de conhecimentos fundamentais para a compreensão do mundo e de seus elementos, pois facilita a resolução de problemas de várias áreas do conhecimento humano e desenvolve o raciocínio visual, além de fixar definições geométricas em forma de gráficos inteiramente interativos.

O GeoGebra utilizado nesta pesquisa e nas atividades escolares é o Classic 5.0.487.0-d, com Java 1.8.0_161-32 bits. Ocupa apenas 247 MB e se inicializa utilizando CAS (FIGURA 2).

Araujo; Nobriga (2010) informam que as versões mais recentes do GeoGebra trazem onze janelas para a realização de vários comandos de operações matemáticas, mais outras que podem ser abertas com abordagens distintas de utilização, que são apresentadas em forma de uma barra oferecida pelo próprio software.

O GeoGebra Classic 5, possui basicamente visíveis, duas janelas: a de álgebra, que permite registrar uma lista de comandos que forem sendo executados em foram de expressões que o software trabalha; e a de visualização, a que ocupa a maior parte da interface do programa, onde são apresentadas as linhas do gráfico cartesiano em forma de 2D. Além disso, o software traz também uma janela especial que exibe em 3D as figuras que são feitas pela janela de visualização em 2D. As onze janelas do GeoGebra Classic 5 estão apresentadas em forma de botões, que abrem cada um menu com opções de operações matemáticas, que podem ser realizadas na janela de visualização 2D ou 3D e mesmo ambas simultaneamente.

O software possui, ainda, ferramentas mais interativas, que possibilitam o usuário realizar diversas formas de anotações, rabiscos virtuais para destaque de objetos, movimentações, ajustes de janelas, entre outras facilidades.

\subsection{A Mini-oficina de GeoGebra}

A utilização do software GeoGebra em uma mini-oficina contribui para solucionar parte dos vários problemas estruturais de ensino matemático. Scheffer 
(2010) comenta que os diferentes softwares contribuem de algum modo para a superação das limitações desse ensino nas escolas.

Giraldo, Caetano e Mattos (2012), ao discutirem as possibilidades oferecidas pelo uso do software GeoGebra no ensino de Matemática, ressaltam que as ferramentas de geometria dinâmica permitem a construção de objetos geométricos de acordo com as propriedades ou relações estabelecidas. Os autores ainda informam que essas características do software permitem aprendizagem mais dinâmica, por onde os discentes conseguem dominar as representações dos espaços, além de se perceber como as figuras geométricas exibem inúmeras possibilidades de cálculo e de comportamento dos números.

Lorenzato (2010) informa que, além da formação dos docentes, contribui para a melhoria da aprendizagem de matemática a constituição de uma mini-oficina* de ensino de matemática, um espaço físico específico destinado à educação dessa disciplina, que favorece uma série de experiências positivas para o aperfeiçoamento da aprendizagem dos discentes.

Turrioni; Perez (2010) explicam que uma mini-oficina ou laboratório tem por objetivo capacitar os docentes de matemática a lidar com as inovações tecnológicas para poder ensinar essa disciplina para os discentes utilizando um espaço específico e altamente moderno que contribui para superar os receios de se aprender a calcular.

Turrioni; Perez (2010) continuam informando que essa mini-oficina precisa atender às realidades educacionais brasileiras, tanto em escolas públicas quanto privadas. Ao ter conhecimento dos dados da educação matemática, os docentes terão competências para capacitar os discentes para que estes tivessem contato com as inovações e novas competências.

O desafio principal para a mudança de postura dos docentes frente às novas formas de educação matemática é de superar a resistência dos mesmos às inovações, pois esses profissionais geralmente não aceitam mudanças ou adaptações rápidas. Como muitos também pertencem às gerações dos imigrantes e dos nativos digitais mais antigos, não se adaptam facilmente às transformações educacionais, pois procuram lecionar seguindo regras preestabelecidas, por representar mais comodidade e facilidade de atuação em sala de aula

\footnotetext{
* Na obra de Lorenzato (2010) emprega-se a palavra laboratório no lugar de mini-oficina.
} 
Silva (2018) destaca que as atividades de matemática com a utilização de um mini-oficina possibilita uma melhor qualidade na aprendizagem dessa disciplina, pois permite a construção contínua do conhecimento. Some-se a isso que os materiais do laboratório possibilitam que o discente seja capaz de resolver exercícios e/ou memorizar diversas fórmulas visualizando o objeto ao mesmo tempo. Com a manipulação dos objetos, com a orientação do docente, os discentes desenvolverão ainda uma compreensão aprofundada dos conceitos matemáticos e poderão ser capazes de conseguir atingir novos degraus do pensamento matemático.

Rêgo; Rêgo (2010) comentam que uma mini-oficina constitui um importante espaço/momento de experimentação para o docente de matemática, que tem a oportunidade de avaliar na prática tudo o que o discente manipula e opera com os recursos de matemática. Os autores ainda informam que é necessário que o docente se atualize com cursos específicos para operá-la.

O software GeoGebra contribui também para interligar vários elementos constituintes de um elemento matemático, de modo que estabelece uma interconexão de cálculos. Por exemplo, a geometria de um cata-vento implica que o software possibilita calcular triângulos, as relações trigonométricas, a superfície, a simetria, os polígonos constituintes, a classificação de ângulos, as medidas do comprimento, do polígono e de outros elementos relacionados a essa figura (SCHEFFER, 2010).

\section{MATERIAL E MÉTODOS}

Um questionário com 3 (três) questões de perguntas foi aplicado para todos os discentes matriculados regularmente na $1^{\text {a }}$ série $M 1$ e na $1^{\text {a }}$ série $M 2$ da escola estadual de ensino fundamental e médio "Padre Antônio Volkers" no ano de 2018 como parte integrante da metodologia desta pesquisa.

A metodologia adotada é qualitativa, com coleta de dados através do questionário aplicado e discussão das principais questões para levantamento de respostas por parte dos discentes pesquisados.

Além disso, discutir-se-ão os resultados através de uma abordagem bibliográfica para dar suporte às observações acadêmicas do pesquisador, destacando-se como os softwares aplicados em educação contribuem positivamente 
para o aperfeiçoamento da aprendizagem e dinamização do ensinar em sala de aula.

\section{RESULTADOS}

A primeira questão do questionário aplicado é: Como você avalia a importância da utilização do software GeoGebra no ensino de álgebra?

A tabela 1 exibe os dados coletados desta pesquisa pela aplicação do questionário.

\begin{tabular}{lrr}
\hline Avaliação & Quantidade & Porcentagem \\
\hline Muito importante & 15 & $47 \%$ \\
Importante & 13 & $41 \%$ \\
Razoavelmente importante & 2 & $6 \%$ \\
Pouco importante & 2 & $6 \%$ \\
Nenhuma importância & 0 & $0 \%$ \\
\hline
\end{tabular}

Tabela 1 - Resultados da pesquisa do questionário dos discentes da EEEFM "Padre Antônio Volkers" Fonte: Elaboração Própria.

Para a maioria dos discentes das duas séries que realizaram a segunda avaliação (47\%) o uso do GeoGebra em suas atividades escolares de matemática foi avaliado satisfatoriamente, com muita importância. Eles observaram que esse software realiza uma grande gama de operações matemáticas que dificilmente conseguem visualizar sem a utilização de um programa especial e por isso se tornaram mais receptivos à sua interface.

Lins (2005) destaca que toda educação matemática, seja esta também processada por meios eletrônicos ou de multimídias, deve ser construída em processos por diversas leis educacionais especiais e ser produzida em significados para todos os indivíduos. Sem isso, a matemática é vazia e sem sentido.

O segundo item desta primeira questão, que aborda sobre a importância do software matemático, $41 \%$ dos discentes das duas séries pesquisadas concordaram com esse item. Os discentes que responderam que o uso do software GeoGebra no ensino de álgebra é muito importante e importante corresponde a $88 \%$ que aprovaram satisfatoriamente esse programa que dinamiza o ensino da matemática. 
A segunda questão abordada: Destaque um aspecto que você considere importante e que contribua para a aprendizagem de função com o uso do software GeoGebra.

Essa questão objetiva como o software pode contribuir para a aprendizagem de matemática pelo discente e como este encara essa tecnologia para seu aperfeiçoamento enquanto usuário e aprendiz.

A tabela 2 exibe os resultados desta segunda questão.

\begin{tabular}{lcc}
\hline & Quantidade & Porcentagem \\
\hline $\begin{array}{l}\text { A possibilidade de desenvolver uma atividade } \\
\text { prática que ajuda a fixar a aprendizagem }\end{array}$ & 12 & $38 \%$ \\
A facilidade na visualização, já que a & 11 & $35 \%$ \\
apresentação se torna minuciosa e clara & & \\
Melhora o trabalho do docente & 3 & $9 \%$ \\
Torna a aula mais dinâmica & 3 & $0 \%$ \\
Cativa e proporciona mais liberdade ao aluno & 0 & $9 \%$ \\
A aprendizagem se dá de forma mais rápida & 3 & \\
e prazerosa & & \\
\hline
\end{tabular}

Tabela 2 - Resultados da segunda questão do questionário para os discentes da EEEFM "Padre Antônio Volkers"

Fonte: Elaboração própria.

O primeiro item desta questão solicita uma resposta para: a possibilidade de desenvolver uma atividade prática que ajuda a fixar a aprendizagem. Para 12 (doze) discentes, ou 38\% dos 32 (trinta e dois) que realizaram a segunda avaliação, responderam esse levantamento, informando que o GeoGebra contribui para a fixação dos conteúdos aprendidos na disciplina de matemática, além de possibilitar uma correspondência entre o que é ensinado e o que é visualizado.

Araújo; Nobriga (2010) atestam que o GeoGebra realmente contribui para haver interligação entre a teoria e a prática, entre os exercícios e sua visualização concreta em forma de imagens. A tecnologia possibilita isso e faz com que os discentes sintam-se motivados a aprender e a querer descobrir mais e manipular resultados.

Gravina (1996) ainda complementa que os softwares de matemática contribuem para realizar essa interligação e que o GeoGebra potencializa os 
recursos da geometria dinâmica, apresentando concomitantemente a representação geométrica e ainda a representação algébrica. Ao dominar esses recursos, o discente se sente integrado no mundo digital e cada vez mais pode contribuir para o aperfeiçoamento da aprendizagem sem praticar indisciplina.

O segundo item foi respondido por 11 (onze) discentes - 35\% do total - que alegam que o GeoGebra possui facilidade de visualização tornando a apresentação minuciosa e clara.

Ao atender essa característica, conforme acrescenta Murari (2005), o software contribui para que o discente se sinta mais seguro e confiante em si mesmo, de modo que este não perca o foco na atenção e nos estudos.

O terceiro item, que aborda sobre que esse software melhora o trabalho do docente, foi respondido afirmativamente por 3 (três) discentes, ou 9\% do total. De fato, como o uso de tecnologias didáticas avançadas, o trabalho do docente fica mais dinâmico e menos atrelado a velhos paradigmas educacionais tradicionalmente repassados durante os cursos de formação. Os discentes percebem isso e valorizam o docente que investe em aperfeiçoamento contínuo e estimulante.

Penteado (2005) informa que o docente tem que sempre enfrentar a zona de risco - que pode ser representada pela atualização ou aperfeiçoamento contínuo para poder oferecer ensino de qualidade e dialogação com seus discentes.

Mais 3 (três) discentes responderam, no quarto item, que o GeoGebra torna a aula mais dinâmica, enquanto que nenhum deles consideraram que esse software consegue cativar e proporcionar mais liberdade para eles, como sugere o quinto item. Os outros 3 (três) discentes, no último item, responderam o GeoGebra torna a aprendizagem mais rápida e prazerosa.

\section{DISCUSSÃO}

A positiva reação da maioria dos discentes frente ao GeoGebra foi devido ao empenho didático de dois docentes de matemática, que organizaram previamente o material para repassá-los no laboratório de informática da instituição escolar. Um docente trabalhou álgebra e outro, com triângulo retângulo e teorema de Pitágoras. Esses mesmos docentes também ajudaram os outros da disciplina de matemática na mini-oficina. Apenas 2 (dois) discentes responderam que o GeoGebra é 
razoavelmente importante (6\%) e outros 2 (dois), que também corresponde a 6\%, assinalaram pouco importante para eles e para sua aprendizagem em matemática. Ninguém optou pelo item nenhuma importância.

De modo geral, esses quatro discentes que não aprovaram esse software foram os que não alcançaram média satisfatória na segunda avaliação e/ou também aqueles que ainda não descobriram o GeoGebra como uma ferramenta fundamental para as atividades de matemática. São muitos os fatores que contribuem para isso, como o desinteresse, a falta de perspectivas para seu futuro profissional, a indisciplina que praticam em sala de aula ou por sofrerem algum problema psicológico.

Muitas vezes, os discentes são nitidamente impacientes e até mesmo rebeldes com as autoridades instituídas, o que lhes podem levar ao isolamento e ao baixo nível de aproveitamento escolar. Ainda são mais suscetíveis à baixa estima, 0 que os levam a comportamentos mais indisciplinares, impedindo-os de aprender adequadamente. Ao manusear os aparelhos eletrônicos eles buscam outras formas de distração ou alheias no mundo virtual e ser desatenciosos ao que está em sua volta.

De modo geral, a pesquisa do questionário mostra que para atrair a atenção dos jovens discentes, as tecnologias portáteis e softwares dinâmicos precisam ser eficazes e possibilitar ao usuário amplo domínio das operações matemáticas de modo que eles sintam-se estimulados a manusear dados e estudar. Assim, a tecnologia, segundo Cherubim (2018), tem que ser a principal aliada dos docentes para realizar a motivação dos discentes.

Da segunda questão do questionário pode-se inferir que os discentes souberam dosar as informações a respeito do GeoGebra, declarando mais que esse software é mais necessário para operar atividades geométricas mais complexas e oferecer respostas com precisão. A aprendizagem foi vista como a maior beneficiária do uso dessa ferramenta em sala de aula, pois sem esse elemento não é possível estudar e nem compreender a ciência e suas características.

A última pergunta foi subjetiva, solicitando aos discentes que deem sugestões para que o docente de matemática possa melhorar a aprendizagem com o uso do software GeoGebra em sala de aula.

A maioria dos discentes que responderam a essa questão escreveram que gostaram muito em ter descoberto e aprendido a manusear o GeoGebra no 
laboratório de informática da escola onde estudam. Alguns deram algumas sugestões como maior utilização do laboratório e uso do telefone em alguns momentos para consultas.

Outros discentes informaram que o GeoGebra lhes ajudou a melhorar o conteúdo, que Ihes facilitou aprender melhor a matemática e como essa ciência realmente funciona e para que serve.

Outros discentes ainda informaram que o software ajuda a visualizar melhor os objetos desenhados nas janelas, contribui para aprender de forma mais dinâmica e até mesmo com mais descontração, o que facilita a aprendizagem.

Aqueles que tiveram baixo rendimento na avaliação escrita informaram que não se interessaram pelo GeoGebra devido a muitos motivos.

De modo geral, os discentes aprovaram o uso desse software após conhecêlo e serem assessorados pelos docentes de matemática. Isso demonstra que seu uso favorece a aprendizagem Outra constatação importante é que os discentes da realmente aprendem melhor quando utilizam livre e responsavelmente tecnologias disponíveis conectadas à internet em dispositivos móveis como o telefone celular, tal como comprovam vários autores já mencionados nesta pesquisa.

Nascimento (2012) complementa que o uso de softwares na educação só vem a contribuir para ampliar o conhecimento dos indivíduos. No que tange à visualização geométrica, o GeoGebra se torna uma das ferramentas matemáticas mais utilizadas, pois facilita os conteúdos, além de favorecer o enriquecimento das metodologias de ensino, contribuir para a fixação de conceitos geométricos e ainda atender às necessidades dos discentes, como a sua preparação para o mercado de trabalho e mais capacitação qualitativa.

De modo geral, podem-se discutir as seguintes contribuições das percepções dos discentes acerca do uso do GeoGebra. O uso do software GeoGebra traz muitas vantagens em relação ao trabalho no papel ou no quadro, como movimentar as figuras em diversas direções, comparar e voltar ao aspecto inicial, algo que não é possível de se realizar em uma aula tradicional, com poucos materiais concretos e ausentes de aparelhos tecnológicos.

É discutível a utilização e eficácia do uso do telefone celular em sala de aula para fins didáticos; na França, por exemplo, sua utilização em escolas está proibida por não promover aprendizagem, mas sim aumento de distração e indisciplina. No estado do Espírito Santo, embora autorizado com ressalvas, o telefone celular 
precisa ser utilizado com extremo cuidado pelos docentes para se efetuar a correta educação matemática.

Os docentes precisam trabalhar com as modernas tecnologias que facilitem a educação matemática, com aprendizagem focada no desenvolvimento do raciocínio lógico dos discentes. Os docentes, se bem assessorados e treinados, conseguem acompanhar as tendências e podem ensinar a utilização do software tão bem como os outros docentes de outras gerações de nativos digitais.

O GeoGebra pôde ser utilizado de vários modos em sala de aula. Nas aulas expositivas o GeoGebra contribuiu para resolver questões em duplas ou individualmente. Outra constatação observada que o software não apenas serviu para trabalhar com mais agilidade, mas também contribuiu para buscar diversos caminhos de resolução de problemas para verificar se o que foi feito está correto. A avaliação das atividades ficou mais qualitativa, pois os discentes puderam manipular mais os dados e memorizar menos as fórmulas matemáticas, o que contribuiu para que aprendessem que buscar a solução de problemas favorece a concentração, a procura de hipóteses e aplicação das leis matemáticas, bem como a sua comprovação.

Com o uso do software os discentes tanto aprendem álgebra matemáticas no papel quanto no computador. No entanto, independentemente do tipo de exercício proposto, o importante é que eles compreendam o conceito, seja utilizando o computador, seja desenhando a lápis. O GeoGebra é uma das ferramentas que possibilita que o discente seja mais autônomo e comprometido com os resultados propostos a ele. Por ser também um programa que se rege por comandos programados, o software já prepara o discente a programar tecnologias que será útil para a sua futura formação tecnológica, buscando novos caminhos para os desafios da sociedade e do mundo capitalista.

Para os docentes de matemática da EEEFM "Padre Antônio Volkers", a adoção do software GeoGebra contribuiu para que os mesmos tivessem seus esforços didáticos após também aprender a utilizá-lo através de uma mini-oficina .

Ao docente têm sido colocadas demandas de naturezas bastante distintas. Em se tratando do ponto de vista social ele tem tido que aprender a conviver mais intensamente com os interesses e pensamento dos discentes e pais no cotidiano escolar e a ter uma maior interação com a comunidade onde a escola está inserida. No campo institucional, ele tem sido solicitado a participar mais ativamente nas 
definições dos rumos pedagógicos e políticos da escola, a definir recortes adequados no universo de conhecimentos a serem trabalhados em suas aulas, a elaborar e gerir projetos de trabalho (PEREZ, 2005).

Saviani (1999) informa que a educação brasileira é dominada por diversas ideologias herdadas de tentativas de reforma educacionais malsucedidas, como o Mobral e a Escola Nova, que promoveram diversos desencontros entre a teoria e a prática. Destaca também o autor que a educação no Brasil, durante muitas décadas do século $X X$, esteve dominada pelas teorias não-críticas e pelas críticoreprodutivistas. As primeiras sinalizavam que a sociedade seria igual se a todos os indivíduos tivessem as mesmas oportunidades de frequentar uma escola, enquanto que as últimas entendiam a educação como um instrumento de discriminação social e de marginalização.

A mini-oficina também apresenta os seguintes obstáculos que precisam ser superados para se fazê-la funcionar, segundo Turrioni; Perez (2010).

O primeiro obstáculo é a falta de motivação dos discentes para trabalhos práticos. O uso do GeoGebra pode acomodá-los fazendo-os a se interessar em realizar projetos alheios. O segundo se refere ao docente, que tem resistência e dificuldades frente às inovações tecnológicas. A formação do profissional é parte responsável por esse quadro devido que também os institutos de ensino superior não investem em aperfeiçoamento com tecnologias em sala de aula por comodidade ou por tradicionalismo.

O terceiro obstáculo se refere à visão limitada dos docentes às novas tecnologias, pois não percebem horizontes que podem ser trilhados por novos componentes tecnológicos. Para superá-lo é necessário que os docentes ou outros profissionais os orientem com visões holísticas e bem desenvolvidas sobre a matemática, para a condução de diferentes estilos de ensino e de aprendizagem. Além disso, novos procedimentos deverão levar em conta fatores sociais, emocionais, organização em sala de aula, relação com outras áreas do conhecimento e do currículo.

O entendimento inadequado do processo de formação do docente é outro obstáculo, pois as normas de se ensinar estão cada vez mais ultrapassadas e já não respondem mais aos novos desafios propostos pelas tecnologias e novos paradigmas educacionais. Em um mundo evoluindo continuamente, é imperioso que 
a escola se adeque às mudanças e ajude a formular respostas para os desafios que surgem a todo instante (HERNANDEZ ET AL., 2000).

O último obstáculo e o mais importante é a falta de oportunidade para o aperfeiçoamento dos docentes, pois as normas curriculares vigentes muitas vezes impedem que esse profissional possa se qualificar ainda mais para poder ministrar suas aulas com mais qualidade e com menos resistência ou dificuldades. De fato, muitos dos imigrantes digitais possuem dificuldades de se aperfeiçoar porque os cursos de graduação não contemplavam as inovações tecnológicas e nem os capacitavam para lecionar em um novo mundo do qual estão vivenciando.

\section{CONCLUSÃO}

A adoção do GeoGebra no contexto educacional da escola "Padre Antônio Volkers" veio a contribuir para a dinamização do conhecimento de matemática e tentar melhorar a aprendizagem dos discentes. Esse software foi apresentado no segundo capítulo desta dissertação com seus recursos tecnológicos, álgebra e operalidade para os usuários, reforçando que sua utilização em sala de aula e fora dela em atividades contribui para o aumento da aprendizagem do discente e serve até mesmo de conhecimentos básicos para cursos tecnológicos mais avançados, como a engenharia.

Quanto aos resultados alcançados, esta pesquisa adotou uma metodologia a utilização do GeoGebra para atingir os objetivos traçados. Com a aplicação de uma atividade avaliativa com cinco questões e de um questionário sobre o software aos

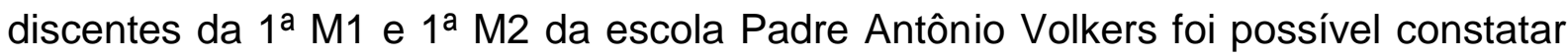
que a utilização dos recursos tecnológicos somente contribuem para melhorar a aprendizagem, aumentando a concentração e possibilitando que as pessoas sintamse parte integrante do aprender. Os resultados mostraram que houve melhoria na aprendizagem das álgebra com o uso correto do GeoGebra, aprendido em uma mini-oficina no laboratório de informática da própria instituição.

Ao utilizar o software GeoGebra a maioria dos discentes respondeu que apresenta diferentes funcionalidades que permitem calcular e executar álgebra geométricas de forma mais rápida e melhor apresentada, de modo que puderam sanar várias dúvidas quanto aos objetos e seus valores. Além disso, informaram 
também que possui uma linguagem que lhes permite relacionar valores e atribuições para construir figuras e sua relação entre si.

A sequência de atividades propostas incentivou os discentes a pensar melhor o papel das modernas tecnologias matemáticas; assim, à medida que as atividades foram progredindo, os discentes puderam por em prática o que aprenderam e conseguiram calcular outras situações matemáticas novas.

Para os docentes da escola "Padre Antônio Volkers", a pesquisa ajudou a revelar que os mesmos também eles carecem de formação mais moderna e atualizada, pois os cursos acadêmicos ainda prestigiam a aplicabilidade de velhos paradigmas educacionais e não contemplam uma abordagem mais abrangente sobre uma educação pautada em rápidas aprendizagem e mediada por modernos aplicativos.

O software de matemática é uma ferramenta que auxilia o discente a raciocinar sobre certos fenômenos. Além disso, é capaz de gerar circunstâncias desafiadoras que exigem procedimentos para encontrar soluções e isso também contribui para gerar novos desafios e outras respostas. Um software, por mais moderno e prático que seja para a educação matemática, não funciona automaticamente como estímulo à aprendizagem, pois necessita da integração entre os programas e os usuários para poder ter sucesso em sala de aula e diversas outras situações.

Como o software GeoGebra oferece possibilidades de exploração geométrica e possui outras características no seu processo de execução, contribui para expandir a capacidade de raciocínio do usuário e o leva a memorizar comandos e álgebra de uma maneira mais rápida e eficaz, o que favorece à construção de estratégias de resolução de problemas.

\section{REFERÊNCIAS}

ARAÚJO, Luis C. L.; NOBRIGA, Jorge C. C. Aprendendo Matemática com o GeoGebra. São Paulo: Exato, 2010.

BERNARDES, Wagner C.; NOTARE, Marcia R. Os Objetos de Aprendizagem e o Desenvolvimento das Habilidades Espaciais. Disponível em: http://seer.ufrgs.br/renote/article/download/44423/28122. Acesso em: 13 out. 2018. 
CHERUBIM, Karina G. Para lidar com a geração Z, professores recorrem a redes sociais. Disponível em: http://mpcidadania.ning.com/profiles/blogs/para-lidar-comgeracao-z-professor-recorre-as-redes-sociais. Acesso em: 16 out. 2018.

GIRALDO, Victor; CAETANO, Paulo; MATTOS, Francisco. Recursos Computacionais no Ensino de Matemática. Rio de Janeiro: SBM, PROFMAT, 2012.

GRAVINA, M. A. Geometria dinâmica uma nova abordagem para o aprendizado da geometria. Belo Horizonte: Brasil, 1996.

FAVA, Rui. Educação 3.0: Aplicando o PDCA nas instituições de ensino. São Paulo: Saraiva, 2014.

HERNANDEZ, Fernando et al. Aprendendo com as inovações nas escolas. Porto Alegre: Artmed, 2000.

HOHENWARTER, M. GeoGebra Quickstart: Guia rápido de referência sobre o GeoGebra. Disponível em: <http://www.mtm.ufsc.br/ jonatan/PET/ geogebraquickstart_pt.pdf>. Acesso em: 15 set. 2018.

LINS, Romulo C. Matemática, monstros, significados e educação matemática. In: BICUDO, Maria Aparecida V.; BORBA, Marcelo C. (orgs.) Educação matemática: pesquisa em movimento. 2 ed. São Paulo: Cortez, 2005.

LORENZATO, Sergio. Laboratório de ensino de matemática e materiais didáticos manipuláveis. In: LORENZATO, Sergio (org.). O Laboratório de Ensino de Matemática na Formação de Professores. 3 ed. Campinas: Autores Associados, 2010.

MURARI, Claudemir. Espelhos, caleidoscópios, simetrias, jogos e softwares educacionais no ensino e aprendizagem de geometria. In: BICUDO, Maria Aparecida V.; BORBA, Marcelo C. (orgs.) Educação matemática: pesquisa em movimento. 2 ed. São Paulo: Cortez, 2005.

NASCIMENTO. Eimard G. A. Avaliação do uso do software Geogebra no ensino de Geometria: Reflexão da prática na escola. Uruguai, 2012.

PENTEADO, Miriam G. Redes de Trabalho: Expansão das possibilidades da informática na educação matemática da escola básica. In: BICUDO, Maria Aparecida V.; BORBA, Marcelo C. (orgs.) Educação matemática: pesquisa em movimento. 2 ed. São Paulo: Cortez, 2005.

PEREZ, Geraldo. Prática reflexiva do professor de matemática. In: BICUDO, Maria Aparecida V.; BORBA, Marcelo C. (orgs.) Educação matemática: pesquisa em movimento. 2 ed. São Paulo: Cortez, 2005. 
RÊGO, Romulo M; RÊGO, Rogéria G. Desenvolvimento e uso de materiais didáticos no ensino de matemática. In: LORENZATO, Sergio (org.). 0 Laboratório de Ensino de Matemática na Formação de Professores. 3 ed. Campinas: Autores Associados, 2010.

SABINO, Vanessa; KON, Fabio. Licenças de Softwares Livres Histórias e Características. São Paulo: CCSL-USP, 2009.

SAVIANI, Dermeval. Escola e democracia. 32. ed. Campinas, SP: Autores Associados, 1999.

SCHEFFER, Nilza F. O LEM na discussão de conceitos de geometria a partir das mídias. In: LORENZATO, Sergio (org.). O Laboratório de Ensino de Matemática na Formação de Professores. 3 ed. Campinas: Autores Associados, 2010.

SILVA, Raquel C. O papel do laboratório no ensino de matemática. Disponível em: http://www.sbem.com.br/files/viii/pdf/07/RE75541815487.pdf. Acesso em: 25 set. 2018.

TURRIONI, Ana M. S. Implementando um laboratório de educação matemática para apoio na formação dos professores. In: LORENZATO, Sergio (org.). 0 Laboratório de Ensino de Matemática na Formação de Professores. 3 ed. Campinas: Autores Associados, 2010. 